\begin{tabular}{ll|l} 
Case Reports in & \multicolumn{1}{c}{\begin{tabular}{l} 
Case Rep Gastroenterol 2019;13:498-507 \\
\cline { 2 - 3 } Gastroenterology
\end{tabular}} & $\begin{array}{l}\text { Dol: } 10.1159 / 000504646 \\
\text { Published online: December 4, } 2019\end{array}$ \\
& $\begin{array}{l}\text { Published by S. Karger AG, Basel } \\
\text { www.karger.com/crg }\end{array}$ \\
\cline { 2 - 2 } & $\begin{array}{l}\text { This article is licensed under the Creative Commons Attribution-NonCommercial } 4.0 \\
\text { International License (CC BY-NC) (http://www.karger.com/Services/OpenAccessLicense). } \\
\text { Usage and distribution for commercial purposes requires written permission. }\end{array}$
\end{tabular}

\title{
Fatty Liver and Systemic Atherosclerosis in a Young, Lean Patient: Rule Out Lysosomal Acid Lipase Deficiency
}

\author{
Maria Zharkova ${ }^{a}$ Tatiana Nekrasova ${ }^{b}$ Vladimir Ivashkin ${ }^{a}$ \\ Marina Maevskaya ${ }^{a}$ Tatyana Strokova ${ }^{c}$ \\ a Vasilenko Clinic of Internal Diseases Propedeutics, Gastroenterology and Hepatology, \\ University Clinical Hospital № 2, I.M. Sechenov First Moscow State Medical University, \\ Moscow, Russia; ${ }^{b}$ Department of Pathology, I.M. Sechenov First Moscow State Medical \\ University, Moscow, Russia; 'Federal Research Center for Nutrition and Biotechnology, \\ Moscow, Russia
}

\section{Keywords}

Fatty liver disease $\cdot$ Hepatosplenomegaly $\cdot$ Lysosomal acid lipase deficiency $\cdot$ Sebelipase alfa

\begin{abstract}
Lysosomal acid lipase deficiency (LALD) is a rare genetic disease characterized by the accumulation of cholesteryl esters and triglycerides in many organs, including the liver, spleen, lymph nodes, bone marrow, and vascular endothelium. Patients with LALD can appear asymptomatic until liver failure or premature sudden death from coronary artery disease, stroke, and aneurysm, which lead to the diagnosis. Herein, we present a diagnostic workup in a young 17-yearold female patient who manifested hepatosplenomegaly, elevated liver enzymes, severe dyslipidemia, and systemic atherosclerosis. Liver biopsy demonstrated over $90 \%$ diffuse microvesicular steatosis, lipid accumulation in Kupffer cells, and birefringent cholesteryl ester crystals. The diagnosis of LALD was proven by the decrease of lysosomal acid lipase activity in dried blood spots and by the detection of two compound heterozygous mutations in the LIPA gene: nonsense mutation G796T (Gly266Term) and splicing site mutation G894A (E8SJM). The patient started enzyme replacement therapy with sebelipase alfa. Following the 1-year treatment, the patient remained asymptomatic, her serum aminotransferase levels were normal,
\end{abstract}




\section{Case Reports in Gastroenterology}

Case Rep Gastroenterol 2019;13:498-507

DOI: $10.1159 / 000504646$

(c) 2019 The Author(s). Published by S. Karger AG, Basel www.karger.com/crg

Zharkova et al.: Fatty Liver and Systemic Atherosclerosis in a Young, Lean Patient: Rule Out Lysosomal Acid Lipase Deficiency

liver density increased due to lipid resorption, and plaque-associated stenosis of carotid artery regressed. Moreover, liver biopsy showed a decrease of cholesteryl ester crystals in Kupffer cells.

(C) 2019 The Author(s)

Published by S. Karger AG, Basel

\section{Introduction}

LALD is a rare autosomal recessive progressive lysosomal storage disease characterized by accumulation of lipids (cholesteryl esters [CE] and triglycerides) in different organs, especially the liver, spleen, lymph nodes, bone marrow, and vascular endothelium. The disease is caused by mutations of the gene encoding lysosomal acid lipase, namely the LIPA gene [1]. The main outcomes of the disease are liver cirrhosis and cardiovascular complications such as coronary artery disease, aneurysm, and stroke [2]. Due to its nonspecific clinical features (overlapping with those of many other diseases), these patients usually pass a very thorough workup before the diagnosis is established. The disease is often misdiagnosed as nonalcoholic fatty liver disease, hereditary dyslipidemia, or cryptogenic cirrhosis. It is essential to diagnose the disease early because of its potential life-threatening complications and availability of the enzyme replacement therapy.

\section{Case Presentation}

A 17-year-old female was hospitalized in the infectious diseases department with a varicella infection. She felt well before and had not undergone any medical evaluation. Examination revealed threefold elevation of alanine transaminase (ALT) and twofold elevation of aspartate transaminase (AST). Tests for viral hepatitis were negative. The patient did not abuse alcohol and did not use any medications. Over the following year, her results demonstrated continuing elevation of liver enzymes. At 18 years of age, she presented for the first time to our clinic.

Upon examination, the patient was thin (BMI was 18). There was no palpable peripheral lymphadenopathy. Her blood pressure was $120 / 80 \mathrm{~mm}$ Hg. The liver edge was palpable $4 \mathrm{~cm}$ below the costal margin, and the spleen edge reached the iliac crest. Splenomegaly in this patient was not accompanied by characteristic stigmas of liver cirrhosis, which argued against intrahepatic portal hypertension. Thus, we focused our further workup on liver enzyme elevation and hepatosplenomegaly.

Complete blood count revealed no pathological findings. Total bilirubin, alkaline phosphatase, gamma-glutamyltransferase, creatinine, glucose, total protein, iron, ferritin, and calcium concentrations were all within reference ranges. Albumin, prothrombin, and the international normalized ratio were normal. ALT was $133 \mathrm{U} / \mathrm{L}$ (reference range, 0-41), and AST was $63 \mathrm{U} / \mathrm{L}$ (reference range, 0-40). Urinalysis results were unremarkable. Autoantibodies were normal, alfa- and gamma-globulins and immunoglobulins showed no changes; ceruloplasmin, serum copper, and 24-h urinary copper level were within reference ranges. Ultrasonography of the abdomen revealed significant hepatomegaly with signs of hyperechogenic parenchyma and splenomegaly. The size of the portal and splenic veins was normal. Esophagogastroduodenoscopy showed no varices.

The results of the examination did not show signs of portal hypertension (normal liver function tests, normal size of portal and splenic vein, no evidence of esophageal or gastric varices, and no ascites). Another cause for serum transaminase elevation, together with enlarged 


\section{Case Reports in Gastroenterology}

Case Rep Gastroenterol 2019;13:498-507

DOI: 10.1159/000504646

(c) 2019 The Author(s). Published by S. Karger AG, Basel www.karger.com/crg

Zharkova et al.: Fatty Liver and Systemic Atherosclerosis in a Young, Lean Patient: Rule Out Lysosomal Acid Lipase Deficiency

liver and spleen, could be infiltrative disease, either storage disease or lymphoproliferative disease, amyloidosis, or multiple myeloma. Computed tomography (CT) imaging was performed to assess liver density, portal and splenic veins, and lymphatic nodes. CT without contrast enhancement (Fig. 1) showed marked hepatomegaly $(22 \times 16 \times 20 \mathrm{~cm})$ and splenomegaly $(20 \times 4 \times 11.5 \mathrm{~cm})$. The most impressive finding was a diffuse decrease of hepatic attenuation up to 23-26 Hounsfield Units (HU) consistent with liver steatosis. In the thoracic aorta and its branches, calcified atherosclerotic plaques were revealed (Fig. 2). Doppler ultrasound also showed a plaque with $30 \%$ stenosis in the left internal carotid artery.

Keeping in mind the possibility of hepatic steatosis and signs of systemic premature atherosclerosis, we tested our patient for homeostatic model assessment of insulin resistance (HOMA-IR) and lipid profile. HOMA-IR was 1.22 (5.7 mU/L × $4.8 \mathrm{mg} / \mathrm{dL} / 22.5)$, which was not consistent with insulin resistance. The lipid profile showed a dramatic dyslipidemia. The total cholesterol (total-c) was $9.46 \mathrm{mmol}$ (366 mg; reference range, 2.5-5.5 mmol [97-213 mg]), triglycerides were $2.3 \mathrm{mmol}$ (reference range, 0-2.26), low-density lipoprotein cholesterol (LDL-c) was $7.66 \mathrm{mmol}$ (296 mg; reference range, 0-3.34 mmol [0-129 mg]), high-density lipoprotein cholesterol (HDL-c) was $0.74 \mathrm{mmol}$ ( $29 \mathrm{mg}$; reference range, 1.15-1.68 mmol [44$65 \mathrm{mg} / \mathrm{dL}])$. These results are consistent with hereditary dyslipidemia such as familial combined hyperlipidemia $(\mathrm{FCH})$ or heterozygous familial hypercholesterolemia $(\mathrm{HeFH})$, and with a rare storage disease (LALD).

To morphologically verify liver disease and evaluate fibrosis stage, liver biopsy was performed (Fig. 3, 4, 5). On light microscopy, a severe diffuse and uniform microvesicular steatosis of more than $90 \%$ hepatocytes, with minimal zonal differences within the hepatic lobule and foci of Kupffer cells with foamy cytoplasm (due to lipid accumulation), located around portal triads and central veins was found. Moderate sclerosis of portal tracts and mild sclerosis of central veins and perivenular sclerosis were detected. No deposits of amyloid were observed. In fresh-frozen tissues under polarized light, birefringent CE crystals in Kupffer cells were revealed.

These histopathologic findings, taken together with elevation of liver enzymes, dyslipidemia, and hepatosplenomegaly, enabled us to suspect LALD. Lysosomal acid lipase activity was measured in dried blood spots. The analysis revealed a significant decrease of lysosomal acid lipase activity $(0.001 \mathrm{~nm} / \mathrm{h} / \mathrm{spt}$ with normal range $0.4-3.0)$. Further genetic testing found two compound heterozygous mutations in the LIPA gene: nonsense mutation G796T (Gly266Term) and splicing site mutation G894A (E8SJM). The last one is the most common mutation observed in LALD. It accounts for $>50 \%$ of the reported pathogenic variants in the European and Hispanic populations [2]. Thus, the patient was diagnosed with LALD.

Considering our patient's young age, hepatic fibrosis, severe organomegaly, and premature atherosclerosis, the patient was started with recombinant human enzyme replacement therapy - sebelipase alfa intravenously at a dose of $1 \mathrm{mg} / \mathrm{kg}$ of body weight every 2 weeks. The patient passed a milestone of 48 weeks of therapy, and her clinical and laboratory dynamics could be analyzed (Fig. 6). Over the whole period of her treatment, the patient felt excellent. Treatment resulted in a very rapid normalization of serum aminotransferases. Her cholesterol level, after dropping, later returned to its initial level, which conflicted with the positive results of her further examination. The results of a CT scan of the abdomen performed in the 24th week of therapy showed a decrease in liver size and a change in liver density from 25 to 40 $\mathrm{HU}$, reflecting a reduction in the fat content in the liver. The next examination after 48 weeks of treatment revealed a drop in the total-c level and LDL-c. Besides continuing treatment, the patient also abstained from meat and dairy products for 6 weeks prior to that laboratory workup. On ultrasound examination of her carotid arteries, a reduction in the atherosclerotic 


\section{Case Reports in Gastroenterology}

Case Rep Gastroenterol 2019;13:498-507

DOI: 10.1159/000504646

(c) 2019 The Author(s). Published by S. Karger AG, Basel www.karger.com/crg

Zharkova et al.: Fatty Liver and Systemic Atherosclerosis in a Young, Lean Patient: Rule Out Lysosomal Acid Lipase Deficiency

plaque in the left carotid artery was observed. The stenosis changed from 30 to $13 \%$. Followup biopsy (Fig. 7, 8) showed a decrease of birefringent CE crystals in Kupffer cells. The fibrosis stage did not progress.

\section{Discussion}

The present case shows the difficulty in recognizing a rare genetic disease - LALD, with nonspecific clinical features. The phenotypic spectrum of LALD ranges from the infantile-onset form (previously known as Wolman disease) to the later-onset form (previously known as CE storage disease [CESD]) [3]. The liver affection in CESD can range from cryptogenic hepatitis with hepatomegaly with or without splenomegaly to liver cirrhosis with liver failure [2]. In this young patient, hepatosplenomegaly without signs of portal hypertension became the initial crucial sign raising concern about storage disease. Acquired storage disease such as amyloidosis was very unlikely because there was no kidney and heart involvement, peripheral neuropathy, and no signs of cholestatic liver injury and serum protein electrophoresis abnormalities. Congenital storage diseases include Niemann-Pick Type B disease, Gaucher disease, glycogenosis, and LALD [4]. Most of these diseases, except LALD, could be ruled out because of no evidence of cytopenia, hypoglycemia, skeletal dysplasia, lung or renal diseases, or nervous system affection in our patient.

Pronounced decrease of liver attenuation on CT was the next step of the differential diagnosis. Normally, the liver parenchymal density is around 50-57 HU. The main causes of diffusely decreased liver attenuation are fatty infiltration and diffuse nonmalignant infiltrative disease (e.g., hepatic amyloidosis). In amyloidosis, radiologic liver density is associated with decreased liver echogenicity on ultrasound examination. In this patient, ultrasonography of the abdomen showed hyperechogenic liver parenchyma, which conflicted with amyloidosis. Therefore, we suspected a massive liver steatosis.

Despite signs of hepatic steatosis, our lean patient did not show signs of metabolic syndrome. She was not predisposed to other relatively common conditions associated with fat accumulation in the liver, such as use of certain drugs (steroids, chemotherapeutic agents, amiodarone, valproic acid, etc.), parenteral nutrition, or starvation. It is worth of mentioning that unlike individuals with metabolic syndrome patients with LALD may not be obese. Therefore, nonobese patients with these liver manifestations may help differentiating LALD from other conditions such as metabolic syndrome [5].

Severe dyslipidemia in a young, lean patient without a family history of cardiovascular diseases also raised suspicion for LALD. Serum lipid levels in LALD may vary, but most children and adults present with elevated total-c and LDL-C and reduced HDL-C levels [2]. In general, CESD may initially be confused with $\mathrm{HeFH}$ and FCH, which are consistent with type IIa and IIb hyperlipidemia [6]. A detailed family history analysis can largely distinguish autosomal dominant disorders (e.g., HeFH, FCH, and polygenic hypercholesterolemia) from autosomal recessive disorders (e.g., LALD). Dyslipidemia in LALD has been associated with atherosclerosis, premature cardiovascular disease, and catastrophic vascular events including stroke and increased mortality [2-4].

Deficiency of lysosomal acid lipase results in reduced hydrolysis of CE and triglycerides and their excessive accumulation within lysosomes. This leads to a specific histology in LALD: diffuse microvesicular or mixed steatosis with minimal zonal differences within the hepatic lobule, large Kupffer cells with lipid droplets [6], and birefringent CE crystals in hepatocytes and/or Kupffer cells in fresh-frozen tissues under polarized light [7]. Microvesicular diffuse 


\section{Case Reports in Gastroenterology}

Case Rep Gastroenterol 2019;13:498-507

DOI: $10.1159 / 000504646$

(c) 2019 The Author(s). Published by S. Karger AG, Basel www.karger.com/crg

Zharkova et al.: Fatty Liver and Systemic Atherosclerosis in a Young, Lean Patient: Rule Out Lysosomal Acid Lipase Deficiency

steatosis is also detected in acute fatty liver of pregnancy and in drug-induced liver injury (valproic acid, antiretroviral therapy), but foamy Kupffer cells are not seen in the above-mentioned conditions. Immunohistochemistry with the lysosomal markers cathepsin D, lysosomal-associated membrane protein 1 and 2, and lysosomal integral membrane protein 2 [7] can also be used in LALD. In our case, pathognomonic birefringent CE crystals in Kupffer cells were detected using polarized light.

The patient was prescribed sebelipase alfa as enzyme replacement therapy. Statins and other lipid-lowering medications have been used with limited success in the control of LDL-c levels and showed mixed results on liver injury and progression of fibrosis $[2,6,8]$. The effect of lipid-lowering agents on accelerated atherosclerosis and cardiovascular outcomes remains unclear. In patients with advanced liver disease, liver transplantation is required, but there is limited information on long-term outcomes after transplantation [2]. Sebelipase alfa is a recombinant human lysosomal acid lipase. To date, eight clinical trials with sebelipase alfa have been finished. Clinical data showed normalization of liver transaminases in the majority of patients, improvement in hepatic fat content, reduction of liver fibrosis, and improvement of atherogenic biomarkers $[8,9]$.

The positive dynamics of enzyme replacement therapy in our patient was supported by the normalization of serum transaminases, reduction of liver steatosis detected by CT, regress of plaque-associated stenosis of the carotid artery, and decrease of CE crystals in Kupffer cells. The decrease of total-c during the first year of treatment was achieved also through a strict fat-free diet, pointing to its necessity in patients with LALD. Anyway, the regression of atherosclerotic plaque was achieved in our patient during enzyme replacement therapy despite persisting mild hypercholesterolemia. That positive result indirectly supported the concept that sebelipase alfa can directly affect the lipid-laden macrophages of vascular endothelium decreasing the plaque.

In summary, patients with LALD such as our patient can appear asymptomatic until stroke, aneurysm, aortocoronary disease, or premature sudden death from liver failure, which lead to the diagnosis. We should involve LALD in our differential diagnosis in cases of fatty liver disease without signs of metabolic syndrome and in cases of cryptogenic liver disease, dyslipidemia, and hepatosplenomegaly.

\section{Acknowledgment}

The authors acknowledge Medical Adviser's Group, part of CRA-club LLC, for assistance in providing technical support in the development of the manuscript.

\section{Statement of Ethics}

The patient agreed with the publication of this case report and gave informed consent.

\section{Disclosure Statement}

The authors declare that they have no conflicts of interest. 
Zharkova et al.: Fatty Liver and Systemic Atherosclerosis in a Young, Lean Patient: Rule Out Lysosomal Acid Lipase Deficiency

\section{Funding Sources}

Manuscript submission was funded by Alexion. Authors requested a medical review of the manuscript from Alexion Pharmaceuticals Inc; Alexion also edited the manuscript in English.

\section{Author Contributions}

All authors contributed to manuscript drafting, draft revisions, and approved the final draft for submission. Zharkova and Strokova were also responsible for the patient management; Nekrasova made the morphological examination of the liver and was responsible for imaging data interpretation.

\section{References}

1 Thelwall PE, Smith FE, Leavitt MC, Canty D, Hu W, Hollingsworth KG, et al. Hepatic cholesteryl ester accumulation in lysosomal acid lipase deficiency: non-invasive identification and treatment monitoring by magnetic resonance. J Hepatol. 2013 Sep;59(3):543-9.

2 Bernstein DL, Hülkova H, Bialer MG, Desnick RJ. Cholesteryl ester storage disease: review of the findings in 135 reported patients with an underdiagnosed disease. J Hepatol. 2013 Jun;58(6):1230-43.

3 Grabowski GA, Charnas L, Du H. Lysosomal acid lipase deficiencies: the Wolman disease/cholesteryl ester storage disease spectrum. Metab. Mol. basis Inherit. Metab. Dis. New York: McGraw-Hill Inc; 2012.

4 vom Dahl S, Harzer K, Rolfs A, Albrecht B, Niederau C, Vogt C, et al. Hepatosplenomegalic lipidosis: what unless Gaucher? Adult cholesteryl ester storage disease (CESD) with anemia, mesenteric lipodystrophy, increased plasma chitotriosidase activity and a homozygous lysosomal acid lipase -1 exon 8 splice junction mutation. J Hepatol. 1999 0ct;31(4):741-6.

5 Hoffman EP, Barr ML, Giovanni MA, Murray MF. Lysosomal acid lipase deficiency. GeneReviews [Internet]Seattle: University of Washington; 2016.

6 Reiner Ž, Guardamagna O, Nair D, Soran H, Hovingh K, Bertolini S, et al. Lysosomal acid lipase deficiency-an under-recognized cause of dyslipidaemia and liver dysfunction. Atherosclerosis. 2014 Jul;235(1):21-30.

7 Hůlková H, Elleder M. Distinctive histopathological features that support a diagnosis of cholesterol ester storage disease in liver biopsy specimens. Histopathology. 2012 Jun;60(7):1107-13.

8 Burton BK, Balwani M, Feillet F, Barić I, Burrow TA, Camarena Grande C, et al. A phase 3 trial of sebelipase alfa in lysosomal acid lipase deficiency. N Engl J Med. 2015 Sep;373(11):1010-20.

9 Wilson DP, Friedman M, Marulkar S, Hamby T, Bruckert E. Sebelipase alfa improves atherogenic biomarkers in adults and children with lysosomal acid lipase deficiency. J Clin Lipidol. 2018 May - Jun;12(3):604-14. 


\section{Case Reports in Gastroenterology}

\begin{tabular}{l|l}
\hline Case Rep Gastroenterol 2019;13:498-507 \\
\hline DOI: 10.1159/000504646 & $\begin{array}{l}\text { @ 2019 The Author(s). Published by S. Karger AG, Basel } \\
\text { www.karger.com/crg }\end{array}$ \\
\hline
\end{tabular}

Zharkova et al.: Fatty Liver and Systemic Atherosclerosis in a Young, Lean Patient: Rule Out Lysosomal Acid Lipase Deficiency

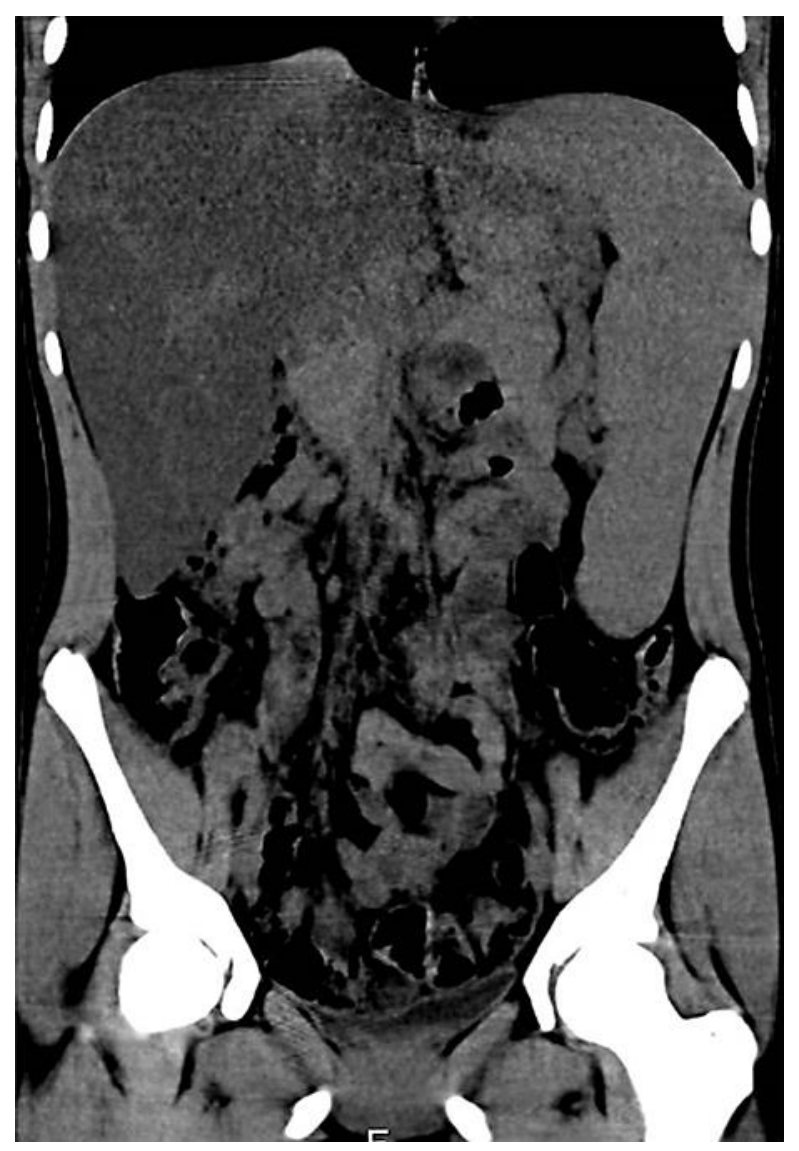

Fig. 1. CT scan of the coronal section of the abdomen showing hepatomegaly $(20 \times 16 \mathrm{~cm})$ with diffuse hepatic attenuation up to $23-26 \mathrm{HU}$ and marked splenomegaly $(20 \times 4 \mathrm{~cm})$.

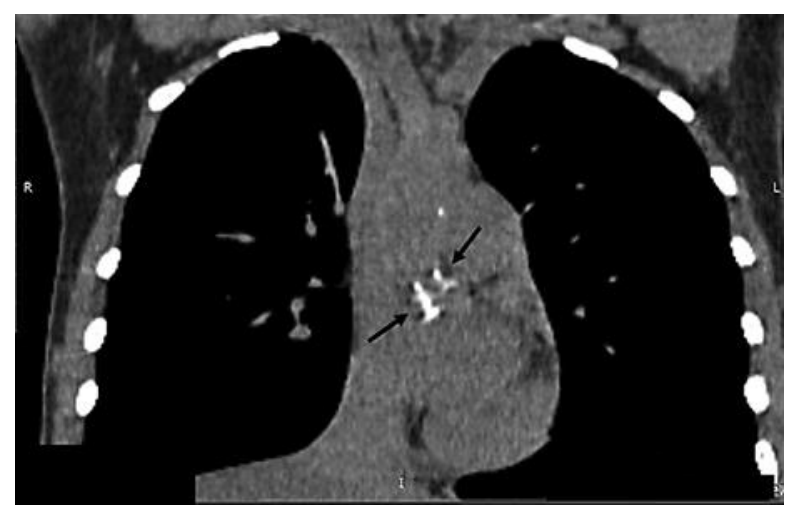

Fig. 2. CT scan of the thoracic cavity showing calcified atherosclerotic plaques (arrows) in the thoracic aorta and its branches. 


\section{Case Reports in Gastroenterology}

\begin{tabular}{l|l}
\hline Case Rep Gastroenterol 2019;13:498-507 \\
\hline DOI: 10.1159/000504646 & $\begin{array}{l}\text { ○ 2019 The Author(s). Published by S. Karger AG, Basel } \\
\text { www.karger.com/crg }\end{array}$ \\
\hline
\end{tabular}

Zharkova et al.: Fatty Liver and Systemic Atherosclerosis in a Young, Lean Patient: Rule Out Lysosomal Acid Lipase Deficiency

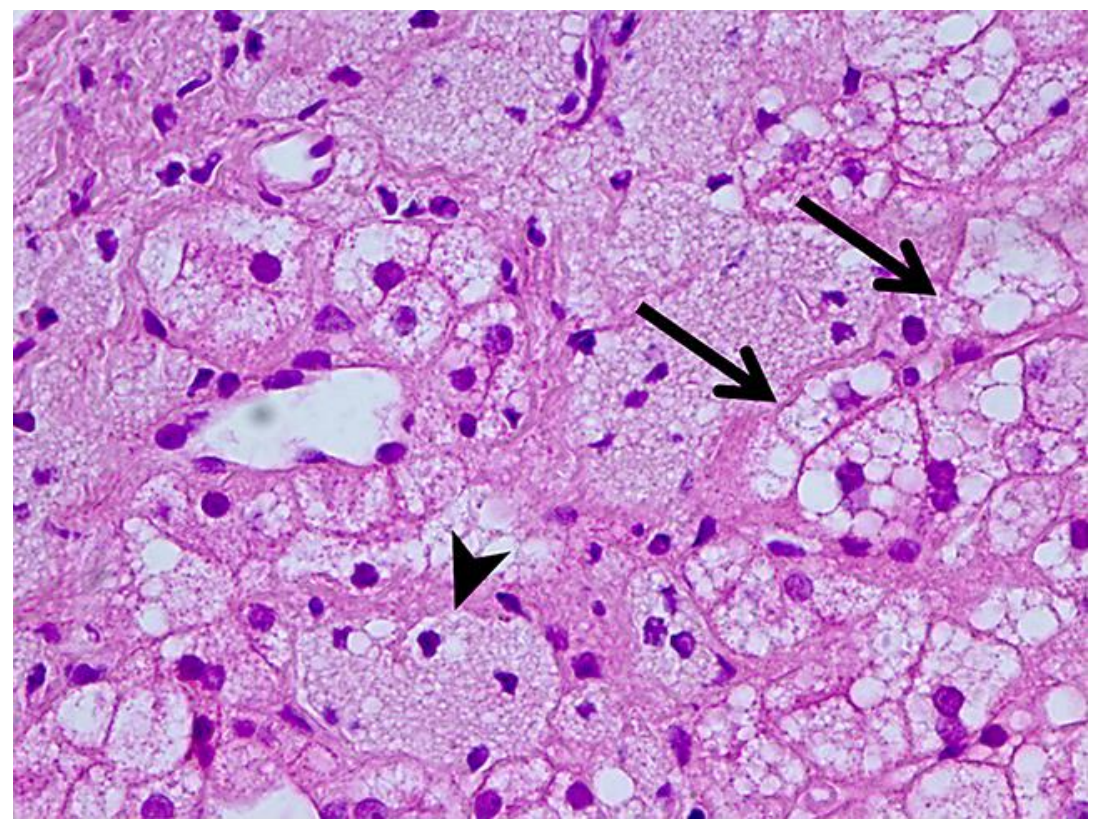

Fig. 3. Liver histopathology. Diffuse, over $90 \%$ of the hepatocytes, uniform microvesicular steatosis (arrows) and lipid accumulation in Kupffer cells (arrowhead). Hematoxylin and eosin. $\times 400$.

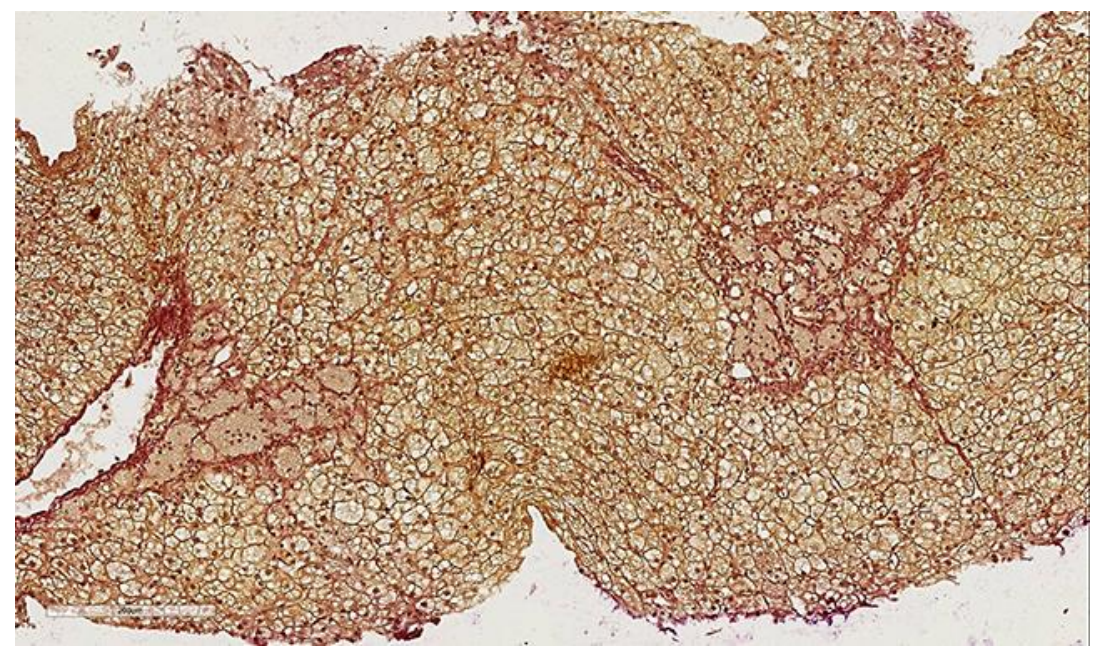

Fig. 4. Liver histopathology. Fibrous septa coming from the portal area and central vein (Van Gieson; ×200). 


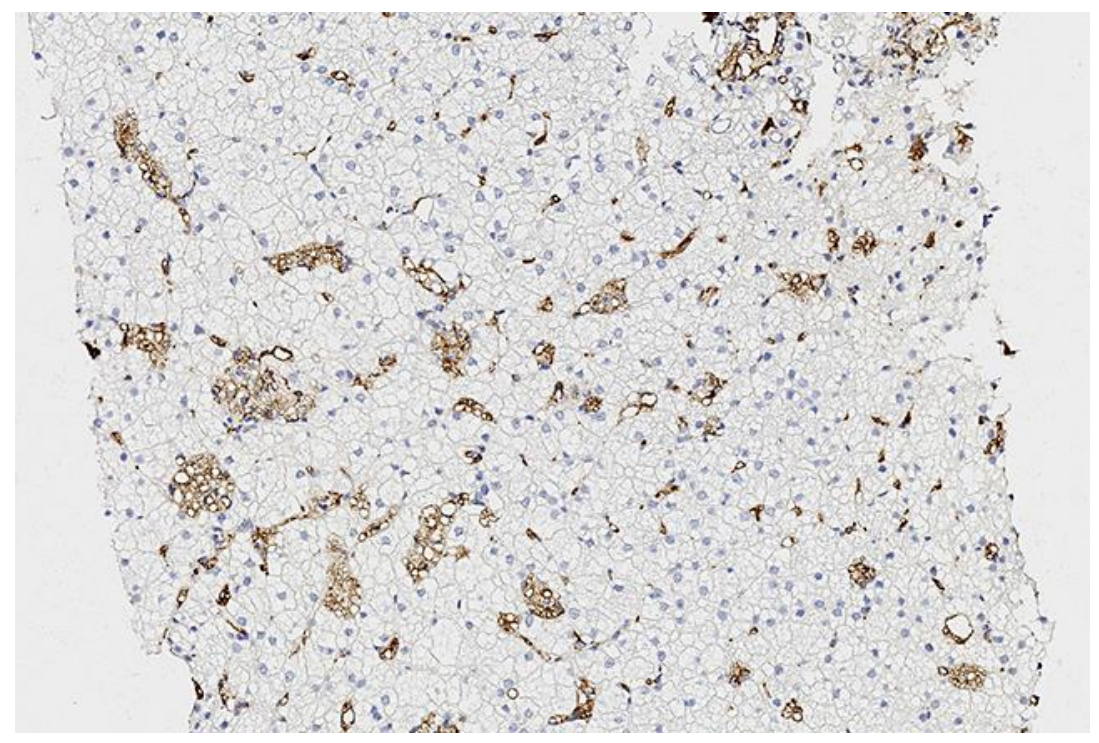

Fig. 5. Liver histopathology. Lipid accumulation in Kupffer cells (Sudan III, frozen samples).

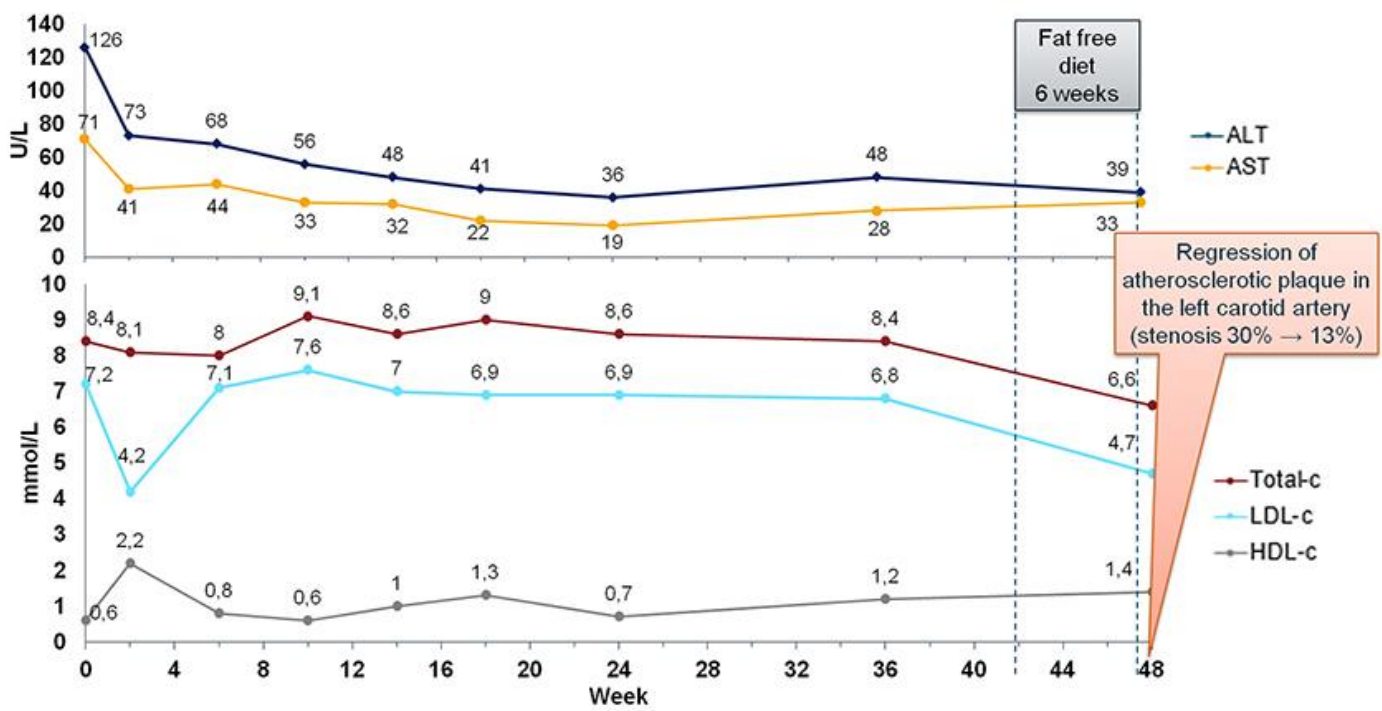

Fig. 6. Laboratory results during sebelipase alfa treatment. ALT, alanine transaminase; AST, aspartate transaminase; total-c, total cholesterol; LDL-c, low-density lipoprotein cholesterol; HDL-c, high-density lipoprotein cholesterol. 


\section{Case Reports in Gastroenterology}

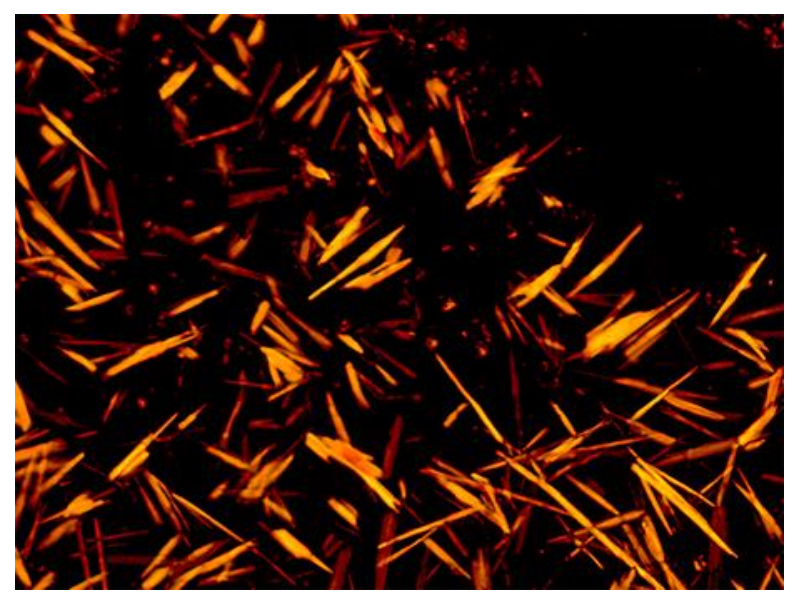

Fig. 7. Frozen liver biopsy samples under polarized light. A great amount of CE crystals in Kupffer cells initially, before the treatment.

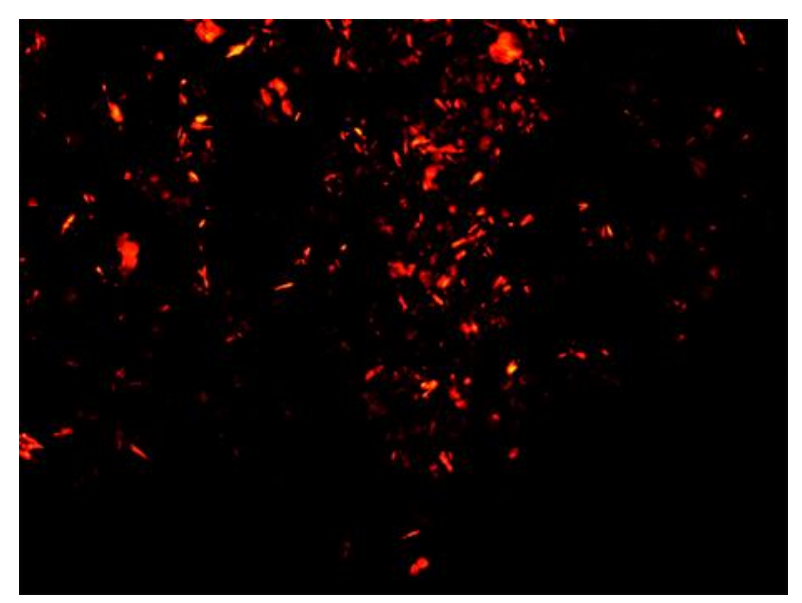

Fig. 8. Frozen liver biopsy samples under polarized light. Significant decrease of CE crystals after 48 weeks of sebelipase alfa treatment. 